\title{
Corrosive extracellular polysaccharides of the rock-inhabiting model fungus Knufia petricola
}

\author{
Romy Breitenbach ${ }^{1,2} \cdot$ Dorothee Silbernagl $^{3} \cdot$ Jörg Toepel $^{4} \cdot$ Heinz Sturm $^{3,5} \cdot$ William J. Broughton $^{1,6}$. \\ Guilherme L. Sassaki ${ }^{6}$. Anna A. Gorbushina ${ }^{1,2,7}$
}

Received: 7 September 2017 / Accepted: 8 December 2017 / Published online: 23 December 2017

(C) The Author(s) 2017. This article is an open access publication

\begin{abstract}
Melanised cell walls and extracellular polymeric matrices protect rock-inhabiting microcolonial fungi from hostile environmental conditions. How extracellular polymeric substances (EPS) perform this protective role was investigated by following development of the model microcolonial black fungus Knufia petricola A95 grown as a sub-aerial biofilm. Extracellular substances were extracted with $\mathrm{NaOH} /$ formaldehyde and the structures of two excreted polymers studied by methylation as well as NMR analyses. The main polysaccharide $(\sim 80 \%)$ was pullulan, also known as $\alpha-1,4-; \alpha-1,6$-glucan, with different degrees of polymerisation. Alpha-(1,4)-linked-Glc $p$ and $\alpha-(1,6)$-linked-Glc $p$ were present in the molar ratios of 2:1. A branched galactofuromannan with an $\alpha-(1,2)$-linked Man $p$ main chain and a $\beta$ - $(1,6)$-linked Gal $f$ side chain formed a minor fraction $(\sim 20 \%)$. To further understand the roles of EPS in the weathering of minerals and rocks, viscosity along with corrosive properties were studied using atomic force microscopy (AFM). The kinetic viscosity of extracellular K. petricola A95 polysaccharides $\left(\approx 0.97 \times 10^{-6} \mathrm{~m}^{2} \mathrm{~s}^{-1}\right)$ ranged from the equivalent of $2 \%(\mathrm{w} / \mathrm{v})$ to $5 \%$ glycerine, and could thus profoundly affect diffusion-dominated processes. The corrosive nature of rock-inhabiting fungal EPS was also demonstrated by its effects on the aluminium coating of the AFM cantilever and the silicon layer below.
\end{abstract}

Keywords EPS $\cdot$ Corrosion $\cdot \alpha$-1,4- and $\alpha$-1,6-glucans $\cdot$ Pullulan $\cdot$ Melanised microcolonial fungi (MCF) $\cdot$ Sub-aerial biofilms (SAB)

Communicated by H. Atomi.

Anna A. Gorbushina

anna.gorbushina@bam.de

1 Department 4 (Materials and Environment), Bundesanstalt für Materialforschung und -prüfung (BAM), Unter den Eichen 87, 12205 Berlin, Germany

2 Department of Biology, Chemistry and Pharmacy, Freie Universität Berlin, Takustr. 3, 14195 Berlin, Germany

3 Division 6.6 (Nanotribology and Nano-Structuring), Bundesanstalt für Materialforschung und -prüfung (BAM), Unter den Eichen 87, 12205 Berlin, Germany

4 Department of Solar Materials, Applied Biocatalytics, Helmholtz Centre for Environmental Research, Permoserstraße 15, 04318 Leipzig, Germany

5 Institute of Machine Tools and Factory Management, TU Berlin, Pascalstr. 8-9, 10587 Berlin, Germany

6 Department of Biochemistry and Molecular Biology, Federal University of Parana, Curitiba, PR CP 19046, Brazil

7 Department of Earth Sciences, Freie Universität Berlin, Malteserstraße 74-100, 12249 Berlin, Germany

\author{
Abbreviations \\ SAB Sub-aerial biofilm \\ EPS Extracellular polymeric substances \\ Galf Galactofuranose \\ Glc $p$ Glucopyranose \\ Man $p$ Mannopyranose \\ MCF Microcolonial fungi
}

\section{Introduction}

Microbial biofilms, one of the most successful forms of life, are held together by an extracellular matrix (Flemming et al. 2016). Almost all microbial groups, including fungi, that produce extracellular polymeric substances (EPS) tend to form biofilms (Blankenship and Mitchell 2006). Fungal cell walls contain chitin and $\beta$-glucans surrounded by a complex network of polysaccharides, glycoproteins and enzymes (Barreto-Bergter and Figueiredo 2014). Extracellular polysaccharides produced by fungi (both filamentous- and yeast-like ones) range from glucans to galactans including 
$\mathrm{N}$-acetylhexosamines, mannans and galactomannan complexes. Many predominant cell-wall polysaccharides in fungi are soluble and can actively participate in EPS formation (reviewed in Breitenbach et al. 2017). Due to a wide variety of biotechnological and medical applications, the $\alpha$-glucan pullulan and the $\beta$-glucan schizophyllan are probably the best characterised fungal extracellular polysaccharides (Prajapati et al. 2013; Zhang et al. 2013). This work is dedicated exclusively to the largely unknown EPS formed by rockinhabiting fungi.

Rock-inhabiting microcolonial fungi (MCF) and black yeasts (orders Chaetothyriales and Dothideomycetes) are amongst the most stress-tolerant eukaryotes known (Gorbushina 2003; Zakharova et al. 2013). Black slow-growing fungi thrive in stressful habitats including hot and cold deserts, rock surfaces (Ruibal et al. 2008; Selbmann et al. 2005) and on material surfaces (Gorbushina 2007; Gorbushina et al. 1993; Ragon et al. 2011). Melanised fungi are also important opportunistic human pathogens (Chowdhary et al. 2015)—and are descendants of the rock-inhabiting taxa that occupy the basic clades of Chaetothyriales and Dothideomycetes (Gueidan et al. 2008; Ruibal et al. 2008). Amongst the most important stress-reduction strategies of MCF are thick melanised cell walls and EPS (Gorbushina et al. 2008; Kuncheva et al. 2013; Pavlova et al. 2011; Selbmann et al. 2005). Production of diverse EPS enables organisms to survive various stresses including temperature fluctuations, low water availability, UV-radiation, nutrient deficiency and even outer space (Onofri et al. 2012; Scalzi et al. 2012; Selbmann et al. 2014). EPS are also involved in interactions of MCF with algae, cyanobacteria and heterotrophic bacteria (Gorbushina and Broughton 2009). EPS of rock-inhabiting bacteria and MCF actively participate in; (a) weathering and soil formation by interaction with substrates; (b) enhance the interaction with symbiotic partners and; (c) increase stress tolerance by retaining water and inhibiting access of external agents to the biofilms (Gadd 2007; Gorbushina and Broughton 2009; Tourney and Ngwenya 2014). To improve our understanding of interactions that guarantee success of MCF in natural environments, we selected the melanised fungus Knufia petricola A95 as a model rockinhabiting fungus (order Chaetothyriales) (Gorbushina and Broughton 2009; Nai et al. 2013; Noack-Schonmann et al. 2014). In earlier work, we had shown that $K$. petricola A95 produces a distinct EPS layer (Gorbushina et al. 2008), but methods to extract and characterise the EPS were needed. Here, we present methods for the quantitative isolation of EPS, for the structural determination of EPS of melanised MCF including those of $K$. petricola A95 and show images of $K$. petricola A95 EPS under the scanning electron microscope. Extracts of $K$. petricola A95 EPS were also used to determine material-relevant properties including viscosity and corrosivity.

\section{Materials and methods}

\section{Fungal strains and growth conditions}

Knufia petricola A95 was isolated from a marble monument in Athens (Greece) (Wollenzien et al. 1997). It is maintained at the Centraalbureau voor Schimmelcultures (as CBS 123,872) in Utrecht, The Netherlands and the Federal Institute for Materials Research and Testing (A95) in Berlin, Germany. K. petricola A95 was cultivated in liquid maltextract broth (MEB). SABs were grown on cellulose acetate filters $(0.45 \mu \mathrm{m}$; Sartorius, Göttingen, Germany) placed on malt-extract agar plates (MEA). After mechanical separation (Nai et al. 2013), $1 \mathrm{ml}$ of the cell suspension was spread onto the filter and incubated at $25^{\circ} \mathrm{C}$ for 7 days.

\section{Extraction and purification of exopolysaccharides}

Biofilms were scraped-off three individual filters. Triplicates were pooled and suspended in PBS buffer $(10 \mathrm{ml})$. EPS were extracted from biofilm suspensions according to Liu and Fang (2002) with modifications. After addition of formaldehyde $(100 \mu \mathrm{l})$, the biofilm suspension was incubated for $1 \mathrm{~h}$ at $4{ }^{\circ} \mathrm{C}$. Then, $4 \mathrm{ml}$ of $1 \mathrm{M} \mathrm{NaOH}$ were added and incubated at ambient temperature for further $3 \mathrm{~h}$. After centrifugation $(7190 \times g, 10 \mathrm{~min})$, the supernatant was transferred to a new tube. Ice-cold absolute ethanol was added to a final concentration of $70 \%(\mathrm{v} / \mathrm{v})$, mixed thoroughly and incubated at $4{ }^{\circ} \mathrm{C}$ for $16 \mathrm{~h}$ to precipitate the polysaccharides. Light microscopy was used to ensure that the cells were not damaged during extraction. The precipitate was washed twice with $70 \%(\mathrm{v} / \mathrm{v})$ ethanol, dried at $45{ }^{\circ} \mathrm{C}$, weighed, re-suspended in deionised water and filter sterilised (cellulose acetate syringe filters; $0.2 \mu \mathrm{m}$; Sartorius). All extractions were performed in triplicate and the experiment was repeated three times. The phenol-sulphuric acid method with glucose as the standard was used to quantify total carbohydrates in the extracts (Dubois et al. 1956).

\section{Monosaccharide composition}

Monosaccharides were determined as their alditol acetate derivatives according to Albersheim et al. (1967) with modifications. Extracellular polysaccharides $(50 \mu \mathrm{g})$ and inositol $(5 \mu \mathrm{g})$ as the internal standard were hydrolysed with $2 \mathrm{M}$ TFA $(200 \mu \mathrm{l})$ at $100{ }^{\circ} \mathrm{C}$ for $3 \mathrm{~h}$, cooled to room temperature and evaporated to dryness. 50\% (v/v) 2-propanol was added to remove TFA. Monosaccharides were reduced overnight with $\mathrm{NaBD}_{4}(1 \mathrm{mg})$ in $1 \mathrm{M}$ ammonium hydroxide, neutralised with acetic acid and evaporated to dryness (methanol was added to decompose excess $\mathrm{NaBD}_{4}$ ). The reduced 
monosaccharides were acetylated with pyridine and acetic anhydride $[100 \mu \mathrm{l} ; 1: 1(\mathrm{v} / \mathrm{v})]$ at $100{ }^{\circ} \mathrm{C}$ for $1 \mathrm{~h}$. Then, the alditol acetates were evaporated to dryness, re-suspended in acetone and identified by retention times as well as electron impact profiles. A mixture of D-galactose, D-glucose and D-mannose with inositol was used as the standard.

\section{Methylation analyses}

Permethylation of polysaccharides was performed using a modified method of Ciucanu and Caprita (2007). Total polysaccharide $(2 \mathrm{mg})$ was dissolved in deionised water $(20 \mu \mathrm{l})$, DMSO $(900 \mu \mathrm{l})$ was added and the sample was sonicated for $45 \mathrm{~min}$. Powdered $\mathrm{NaOH}(30 \mathrm{mg})$ and an excess of solid $\mathrm{NaOH}(60 \mathrm{mg})$ were added to each sample which were again sonicated for $45 \mathrm{~min}$, then stirred at room temperature for another $45 \mathrm{~min}$. Methyl iodide $(350 \mu \mathrm{l})$ was added and the solutions were sonicated for $30 \mathrm{~min}$. More methyl iodide $(100 \mu \mathrm{l})$ was then added and the mixtures stirred at room temperature for a further $45 \mathrm{~min}$. Permethylated polysaccharides were extracted with chloroform, the organic phase was washed three times with deionised water and evaporated to dryness. Thereafter, the samples were hydrolysed, reduced and acetylated as described above (preparation of alditol acetates). Identification of partially methylated alditol acetates was based on retention times as well as mass fragmentation patterns of standards synthesised as described subsequently.

\section{Preparation of PMAA standards}

Permethylated alditol acetate (PMAA) standards were synthesised according to Sassaki et al. (2005) with the modifications of Wang et al. (2007). Briefly, D-galactose, D-glucose and D-mannose (each $60 \mathrm{mg}$ ) were refluxed in $2 \%$ $\mathrm{MeOH}-\mathrm{HCl}$ at $70{ }^{\circ} \mathrm{C}$ for $16 \mathrm{~h}$, neutralised with an excess of $\mathrm{NaHCO}_{3}$, filtered and evaporated to dryness. Methyl glycosides were dissolved in DMF (2 ml) with $\mathrm{BaO}(200 \mathrm{mg})$, $\mathrm{Ba}(\mathrm{OH})_{2} \cdot 8 \mathrm{H}_{2} \mathrm{O}(10 \mathrm{mg})$ and methyl iodide $(1 \mathrm{ml})$. Samples were stirred in the dark and aliquots $(300 \mu \mathrm{l})$ were removed at $1 \mathrm{~h}$ intervals, evaporated to dryness and derivatised to PMAAs as described above (preparation of alditol acetates). After $3 \mathrm{~h}$ for glucose and mannose (4 h for galactose) aliquots contained all substitution patterns necessary for analysis and were used for PMAA identification of exopolysaccharides. Linkage types of the synthesised PMAAs were assigned by comparison with mass spectra (Sassaki and Souza 2013).

\section{Gas chromatography-mass spectrometry (GC-MS) analyses}

GC-MS analyses were performed using a $6890 \mathrm{~N}$ Network Gas Chromatograph linked to a 5973 Network mass selective detector (Agilent, Santa Clara, CA, USA) with $\mathrm{He}$ as the carrier gas. Permethylated alditol acetates were injected onto a fused silica HP-5MS capillary column $(30 \mathrm{~m} \times 0.25 \mathrm{~mm} \times 0.25 \mu \mathrm{m})$. Chromatographic conditions: injector temperature $-220^{\circ} \mathrm{C}$; injection volume $-1 \mu \mathrm{l}$; temperature of the ion-source $-230{ }^{\circ} \mathrm{C}$ and temperature of the quadrupole $-150{ }^{\circ} \mathrm{C}$; acquiring mode - scan, from $\mathrm{m} / \mathrm{z} 40$ to $\mathrm{m} / \mathrm{z} 500$. Alditol acetates were analysed using the following temperature programme: $100{ }^{\circ} \mathrm{C}$, held for $2 \mathrm{~min}, 100$ to $180{ }^{\circ} \mathrm{C}$ at $10^{\circ} \mathrm{C} \mathrm{min}^{-1}$, held for $2 \mathrm{~min}, 180{ }^{\circ} \mathrm{C}$ to $190{ }^{\circ} \mathrm{C}$ at $1{ }^{\circ} \mathrm{C} \mathrm{min}{ }^{-1}$, held for $4 \mathrm{~min}, 190{ }^{\circ} \mathrm{C}$ to $240{ }^{\circ} \mathrm{C}$ at $10{ }^{\circ} \mathrm{C} \mathrm{min}{ }^{-1}$, held for $5 \mathrm{~min}$, then to $280^{\circ} \mathrm{C}$ at $20^{\circ} \mathrm{C} \mathrm{min}^{-1}$, held for $5 \mathrm{~min}$. PMAA were analysed with the temperature programme: $80-120{ }^{\circ} \mathrm{C}$ at $5{ }^{\circ} \mathrm{C} \mathrm{min}-1$, held for $1 \mathrm{~min} ; 120-230^{\circ} \mathrm{C}$ at $3{ }^{\circ} \mathrm{C} \mathrm{min}{ }^{-1}$, held for $1 \mathrm{~min}$; to $280^{\circ} \mathrm{C}$ at $20^{\circ} \mathrm{C} \mathrm{min}^{-1}$, held for $5 \mathrm{~min}$.

\section{Fourier transform infrared (FTIR) spectroscopy}

For FTIR spectroscopy, $10 \mu \mathrm{l}$ of EPS solution was placed on a ZnSe-crystal (Korth Kristalle GmbH, Kiel, Germany) and dried at $45{ }^{\circ} \mathrm{C}$ for $30 \mathrm{~min}$. The infrared spectra were recorded with a FTIR spectrometer (Vertex 70, Bruker Optics, Karlsruhe, Germany) coupled with an infrared microscope (Hyperion 3000, Bruker Optics). The spectra were measured in the absorbance mode in the frequency range 4000-800 $\mathrm{cm}^{-1}$ with a spectral resolution of $4 \mathrm{~cm}^{-1}$. Spectra were baseline corrected and the $\mathrm{CO}_{2}$ peak removed. The mean value of at least five spectra was calculated.

\section{Nuclear magnetic resonance spectroscopy}

Extracellular polysaccharides $(2 \mathrm{mg}$ ) were dissolved in $200 \mu \mathrm{l}$ of $\mathrm{D}_{2} \mathrm{O}$ and samples loaded into $5 \mathrm{~mm}$ Shigemi tube (Shigemi Inc, Allison Park, PA, USA). The nuclear magnetic resonance spectra were obtained using a Bruker Avance III 14.1 T spectrometer equipped with an inverse $5-\mathrm{mm}$ probe head (QXI) at $323 \mathrm{~K} .1 \mathrm{D}{ }^{1} \mathrm{H}-\mathrm{NMR}$ at $600 \mathrm{MHz}$ were performed after $90^{\circ}(\mathrm{p} 1)$ pulse calibration. Pre-saturation of residual HDO was carried out with the pulse programme zgpr, using a relaxation delay $=1.0 \mathrm{~s}$, number of time domain points $=65,536$ and acquisition time $=5.1 \mathrm{~s}$ to obtain a spectral width of $6393 \mathrm{~Hz}$, using 32 data points. ${ }^{1} \mathrm{H}$ and ${ }^{13} \mathrm{C}$ chemical shifts were determined by 2D-NMR analyses using HSQC, COSY and DOSY. HSQC hetero-nuclear correlations via double inept transfers with decoupling during acquisition, using sensitivity improvement trim pulses in inept transfer and shaped pulses for all $180^{\circ}$ pulses on the ${ }^{13} \mathrm{C}$ channel, complied in the pulse programme hsqcetgpsisp2.2 using $6393 \mathrm{~Hz}\left({ }^{1} \mathrm{H}\right)$ and $24,900 \mathrm{~Hz}\left({ }^{13} \mathrm{C}\right)$ widths and a recycle delay of $1.160 \mathrm{~s}$. The spectra were recorded for quadrature detection in the indirect dimension, using 16 scans per series of $2048 \times 256$ data points with zero 
filling in F1 (2048) prior to Fourier transformation. DOSY was carried out using stimulated echo and LED by bipolar gradients for diffusion and two spoil gradients with water pre-saturation (ledbpgpr2s). Spectra were acquired using 16 scans per series of $8 \mathrm{~K} \times 32$ data points with linear gradients of 32 steps 2-96\%, diffusion times of $0.1 \mathrm{~s}$ and the length of the square diffusion-encoding gradient pulses of $1 \mathrm{~ms}$. The 2D-DOSY spectra were processed in the exponential mode on Topspin 3.2 (Bruker BioSpin Corporation, Billerica, MA, USA).

\section{EPS viscosity measurements by atomic force microscopy (AFM)}

To measure viscosity, a silicon cantilever (160ACNN, OPUS, NanoAndMore, Watsonville, CA, USA, $f_{\text {res,air }}=269 \mathrm{kHz}, k_{\mathrm{c}}=28 \mathrm{~N} / \mathrm{m}$ ) with an Asylum MFP3D AFM (Oxford Instruments Asylum Research, Inc., Santa Barbara, CA, USA) was used and power density spectra (PDS) of thermally excited vibrations were recorded. At the resonance frequency $f_{\text {res }}$, the spectra showed a maximum which either could be described by means of a single harmonic oscillator (SHO) (Van Eysden and Sader 2007) or by a Lorentzian peak shape (Franosch et al. 2011). To determine the viscosity of the extracts, a series of measurements on five mixtures of water and glycerine $(2-20 \% \mathrm{v} / \mathrm{v})$ were made to calibrate the sensing system.

\section{Supporting methods for AFM cantilever surface layer examination after fungal EPS contact}

To demonstrate the corrosive nature of $K$. petricola A95 extracellular polysaccharides, a commercially available silicon cantilever (Pointprobe-Plus-NCHR, Nanosensors, Neuchatel, Switzerland: $125 \mu \mathrm{m}$ length, $30 \mu \mathrm{m}$ width, $4 \mu \mathrm{m}$ thickness) covered with a thin film of aluminium (approximate film thickness $<10 \mathrm{~nm}$ ), was immersed in solutions of the polysaccharides. An infrared laser beam $(860 \pm 20 \mathrm{~nm})$ was directed onto the aluminiumcovered reverse-side of the cantilever and reflected onto a photodiode. Comparative topography scans were performed with the Asylum MFP3D AFM in Tapping Mode. Aluminium dissolution from the cantilever surface was demonstrated with energy-dispersive X-ray analyses (EDX, EDAX Inc., NJ, USA); the electron energy was $15 \mathrm{kV}$ (FEI XL 30, LaB6, Eindhoven, The Netherlands). The presence of adsorbed organic material on top of the aluminium layer was excluded by Confocal Raman Spectroscopy (custom-made by WITec, Ulm, Germany) of the immersed cantilever.

\section{Results and discussion}

\section{Culture of K. petricola A95 and preparation of extracellular polysaccharides}

Culture conditions at the border between solid surfaces and the atmosphere differ significantly from those in liquid culture. For example, when fungal cells are cultivated in liquid media, practically no EPS is directly observed and for this reason we decided to study the characteristics of EPS formed during sub-aerial growth. Although growth conditions favouring sub-aerial biofilm development yield only low amounts of EPS, this experimental setup should make the data relevant to the natural habitat of rock-inhabiting MCF.

In contrast to the black yeast $A$. pullulans (which produces the EPS pullulan) that releases large amounts of EPS into its surroundings, the surface of A95 biofilms appears dry (Fig. 1). Most EPS are tightly bound to the cells and must be detached prior to analysis. Different chemical and physical extraction methods exist (Liu and Fang 2002; Pellicer-Nacher et al. 2013) but earlier work (Comte et al. 2006; Liu and Fang 2002) suggested that pre-treatment with formaldehyde and extraction with sodium hydroxide gave the highest extraction efficiency. Using these methods, the yields of crude $K$. petricola A95 EPS grown on malt-extract agar were about $103 \mathrm{mg} \mathrm{g}^{-1}$ cell dry weight.
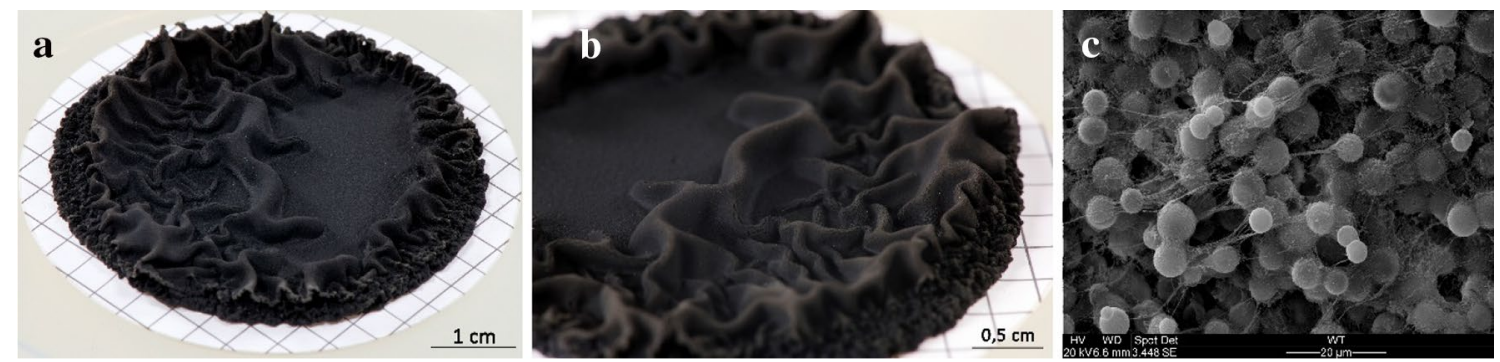

Fig. 1 K. petricola A95 biofilms: a growing on cellulose acetate filters, b close-up view of the sub-aerial biofilm surface, $\mathbf{c}$ scanning electron microscopy of this biofilm surface 


\section{Fourier transformed infrared (FTIR) spectroscopy}

FTIR spectra of the crude EPS revealed typical functional groups (Fig. 2). A broadband around $3286 \mathrm{~cm}^{-1}$, represents the stretching vibration of both the hydroxyl groups of carbohydrates and amino groups of proteins (Fang et al. 2014; Liang et al. 2010). A weak absorption band at $2929 \mathrm{~cm}^{-1}$ is related to the asymmetrical $\mathrm{C}-\mathrm{H}$ stretching vibration of aliphatic $\mathrm{CH}_{2}$-groups (Fang et al. 2014; Liang et al. 2010) while bands at $1658-1552 \mathrm{~cm}^{-1}$ were assigned to $\mathrm{C}=\mathrm{O}$, $\mathrm{C}=\mathrm{N}$ and $\mathrm{C}-\mathrm{N}$ of amide $\mathrm{I}$ and amide II vibrations in the presence of proteins (Fang et al. 2014). Other characteristic carbohydrate bands at $1440-1350 \mathrm{~cm}^{-1}$ represent the $\mathrm{C}-\mathrm{H}$ bending of $\mathrm{CH}_{2}$ and $\mathrm{CH}_{3}$ (Mota et al. 2013). The $\mathrm{C}=\mathrm{O}$ stretching vibration typical of uronic acids $\left(1730 \mathrm{~cm}^{-1}\right.$, if present), could not be detected (Mota et al. 2013). The strong band at $1021 \mathrm{~cm}^{-1}$ and a weak band at $1150 \mathrm{~cm}^{-1}$ were correlated with the $\mathrm{C}-\mathrm{O}-\mathrm{C}$ stretching vibration of carbohydrates (Fang et al. 2014). In addition to carbohydrates, these results revealed the presence of proteins and the absence of uronic acids in the EPS of $K$. petricola A95.

\section{Structure of K. petricola A95 extracellular polysaccharides}

After hydrolysis, sugar residues were converted to alditol acetates. GC-MS analyses demonstrated that the extracted water-soluble polysaccharides mainly consisted of glucose $(66.7 \%)$ with smaller amounts of mannose $(20.6 \%)$ and galactose $(12.7 \%)$, indicating a heteropolysaccharide. To characterise the glycosidic linkage pattern of the isolated polysaccharide, methylation analyses were performed. The presence of three different non-reducing end units-2,3,4,6- $\mathrm{Me}_{4}$-Glcp (7.8\%), 2,3,5,6-Me $\mathrm{Me}_{4}$-Gal $f(4.1 \%)$ and 2,3,4,6- $\mathrm{Me}_{4}-\mathrm{Man} p(1.6 \%)$ as well as the derivatives 2,4- $\mathrm{Me}_{2}-\mathrm{Glc} p(4.4 \%)$ and 2,6-- $\mathrm{Me}_{2}$-Glcp $(4.7 \%)$ were indicative of one complex branched heteropolysaccharide or more than one polymer (Table 1). High amounts of 2,3,6- $\mathrm{Me}_{3}-$

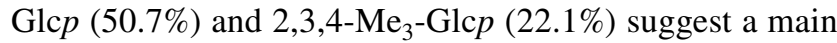
chain probably composed of $(1,4)$-linked glucopyranose and $(1,6)$-linked glucopyranose. Proportions of approximately $2: 1$ in the methylated alditol acetates of extracellular polysaccharides were also found in the extracellular $\alpha$-glucan pullulan of the black yeast $A$. pullulans (Bender et al. 1959). Pullulan is a linear homo-polysaccharide comprising maltotriose trimers joined by $\alpha-(1,6)$ glycosidic linkages. The internal glucose units within maltotriose trimers are connected by $\alpha-(1,4)$ glycosidic bonds (Cheng et al. 2011). Only

Table 1 Partially $O$-methylated alditol acetates obtained by methylation analyses of $K$. petricola A95 extracellular polysaccharides

\begin{tabular}{|c|c|c|}
\hline $\begin{array}{l}\text { Partially } O \text {-methylated } \\
\text { alditol acetates }\end{array}$ & $\begin{array}{l}\text { K. petricola A95 } \\
(\mathrm{mol} \%)\end{array}$ & Linkage type \\
\hline 2,3,4,6- $\mathrm{Me}_{4}-\mathrm{Glc} p$ & 7.8 & Glcp- $(1 \rightarrow$ \\
\hline $2,3,4,6-\mathrm{Me}_{4}-\mathrm{Man} p$ & 1.6 & $\operatorname{Man} p-(1 \rightarrow$ \\
\hline $2,3,5,6-\mathrm{Me}_{4}-\mathrm{Gal} f$ & 4.1 & Galf- $(1 \rightarrow$ \\
\hline 3,4,6- $\mathrm{Me}_{3}-\mathrm{Man} p$ & 2.0 & $2 \rightarrow)-\operatorname{Man} p-(1 \rightarrow$ \\
\hline $2,4,6-\mathrm{Me}_{3}-\mathrm{Glc} p$ & $\operatorname{Tr}$ & $3 \rightarrow)-$ Glcp- $(1 \rightarrow$ \\
\hline 2,3,6- $\mathrm{Me}_{3}-\mathrm{Glc} p$ & 50.7 & $4 \rightarrow)-$ Glcp- $(1 \rightarrow$ \\
\hline $2,3,4-\mathrm{Me}_{3}-\mathrm{Glc} p$ & 22.1 & $6 \rightarrow)$-Glcp-(1 $\rightarrow$ \\
\hline $2,3,5-\mathrm{Me}_{3}-\mathrm{Gal} f$ & 2.6 & $6 \rightarrow)-G a l f-(1 \rightarrow$ \\
\hline 2,6- $\mathrm{Me}_{2}-\mathrm{Glc} p$ & 4.7 & $3,4 \rightarrow)-\mathrm{Glc} p-(1 \rightarrow$ \\
\hline 2,4- $\mathrm{Me}_{2}-\mathrm{Glc} p$ & 4.4 & $3,6 \rightarrow)-\mathrm{Glc} p-(1 \rightarrow$ \\
\hline
\end{tabular}

$\operatorname{Tr}$ traces
Fig. 2 Fourier transformed infrared (FTIR) spectrum of EPS isolated from $K$. petricola A95. The spectrum represents the mean value of five recorded spectra, is baseline corrected and relieved of the $\mathrm{CO}_{2}$ peak

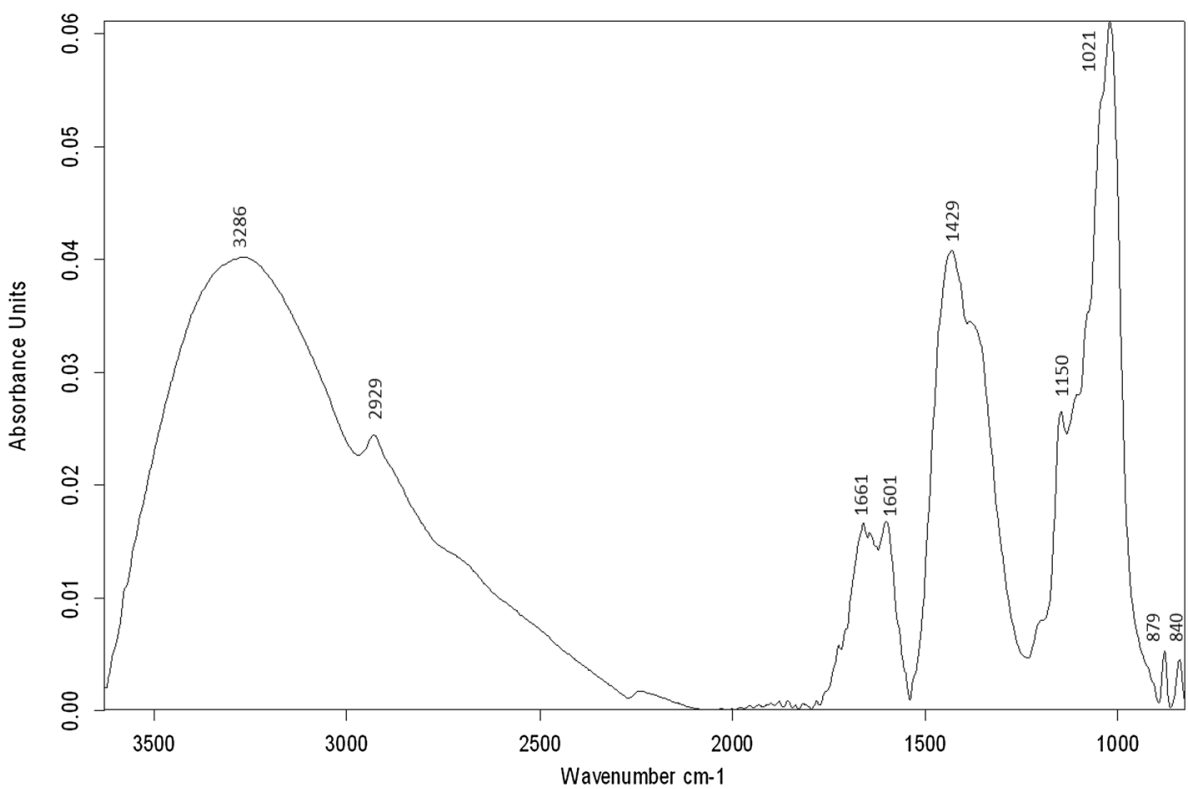


traces of (1,3)-linked glucopyranose, shown by the presence of the derivative 2,4,6- $\mathrm{Me}_{3}$-Glc $p$, could be found by methylation analyses. Other linkage types, including $\alpha-(1,3)$ and even $\beta-(1,3)$ and $\beta-(1,6)$ were found in the pullulan chain of different strains (Bouveng et al. 1962; Fujii et al. 1984; Sowa et al. 1963). The presence of 2,3,6- $\mathrm{Me}_{3}-\mathrm{Glc} p$ and 2,3,4-Me $\mathrm{M}_{3}$-Glc $p$ in similar proportions to those found in pullulan, indicates that $K$. petricola A95 mainly produces a pullulan-like polymer. It can also be concluded from the presence of 3,4,6- $\mathrm{Me}_{3}-\mathrm{Man} p(2.0 \%)$ and 2,3,5- $\mathrm{Me}_{3}$-Galf (2.6\%) (two strong signals at $\delta 5.493$ and 5.109 shown in the ${ }^{1} \mathrm{H}$ NMR spectra of extracellular polysaccharides giving ${ }^{3} J_{\mathrm{H} 1-\mathrm{H} 2}$ of 3.84 and $3.68 \mathrm{~Hz}$, respectively) that $K$. petricola A95 secretes a second polymer, composed of $(1,2)$-linked mannopyranose and $(1,6)$-linked galactofuranose. Small signals were also observed in the anomeric region at $\delta 5.058$, 5.204 and 5.517 which suggest more than one polysaccharide was contained in the fraction. 2D-COSY analyses of vicinal couplings, mainly $\mathrm{H} 1-\mathrm{H} 2$ crossed peak correlations belonging to $\alpha$-glucopyranosyl ring as far the other hydrogens of the molecules were determined (data not shown). Edited HSQC analyses were used to observe the glycosidic linkages and anomeric configuration of the polysaccharides in the mixture, of the main pullulan-like polysaccharide. The anomeric region of the polysaccharide showed characteristic signals with chemical shifts attributed to $\alpha$-linked Glc $p$ units at $\delta 100.3 / 5.493$ and 100.0/5.516, corresponding to 4-O-substitution and at $\delta 98.2 / 5.109$ that were attributed to 6-O-substituted units (Fig. 3). These O-substitutions influenced ${ }^{1} \mathrm{H}$ and ${ }^{13} \mathrm{C}$ chemical shifts and were confirmed due to the presence of signals at $\delta 78.5 / 3.768$ and 77.6/3.790, which indicated direct substitutions at C-4 of the O-4. In the negative phase of HSQC, the C-6 substitution at $\delta 66.9 / 4.09,3.937$ was observed, corroborating the presence of $\alpha$-(1,6)-linked glucopyranosyl units. The minor cross-peak correlation in the anomeric zone at $\delta 108.0 / 5.204$ was attributed to $\beta$-Gal $f$ units substituted at $\mathrm{O}-6$, which was confirmed by detection of a negative phase signal at $\delta 69.4 / 4.021,3.798$. In addition, the correlations at $\delta 99.6 / 5.058$ and $102.3 / 5.204$ were typical of $\alpha-(1,2)$-linked-Man $p$, belonging to the main chain and non-reducing terminal units, respectively (Fig. 3). Confirmation of C-2 substitution was obtained by the detection of the signal at $\delta 78.5 / 4.008$ and the non-substituted C-2 of $\alpha$-D-Man $p$ non-reducing ends at $\delta 70.3 / 4.227$, which agreed with previous studies (Kobayashi et al. 1995; Vinogradov et al. 1998). 2-D diffusion-ordered spectroscopy of (Fig. 4) showed a pullulan with different degrees of polymerisation (DP), since the correlations of $1 \mathrm{H}$ at $\delta 5.493$ and 5.109 and $\log D$ had values ranging from -10.56 to -10.16 , giving estimated molecular masses of 117.1-17.8 kDa, respectively. The heterogeneous profile of extracellular polysaccharides was also confirmed by HPSEC analyses (S1). Additionally, DOSY correlations at $\delta 5.204$ and 5.058, which had $\log D$ values of $-10,089$ to $-10,011$, suggested an additional polysaccharide in the biofilm, a galactofuromannan with an estimated $M_{\mathrm{w}}$ varying ranging from 8.7 to $12.6 \mathrm{kDa}$. The latter probably consists of a branched galactofuromannan with a $\alpha-(1,2)$-linked-Man $p$ main chain attached by $\beta-(1,6)$ Gal $f$ side chains, such as those found in the pathogenic yeast Exophiala jeanselmei (Sassaki et al. 2011). Thus, the extracellular polysaccharides of K. petricola A95 biofilms comprise two major components: a pullulan (80\%) similar to that found in Aureobasidium (Dothideomycetes) and a galactofuromannan (20\%) as in Exophiala (Chaetothyriales). It is interesting that $K$. petricola (Chaetothyriales) being a rock-inhabiting ancestor of Exophiala shares specific EPS
Fig. 3 2-D-edited HSQC NMR spectra; the positive phase (black) corresponded to $\underline{\mathrm{CH}}$, and the negative phase (red) corresponded to $\underline{\mathrm{CH}_{2}} \cdot{ }^{1} \mathrm{H} /{ }^{13} \mathrm{C}$ NMR signals of $K$. petricola A95 extracellular polysaccharide mixtures determined by COSY and HSQC

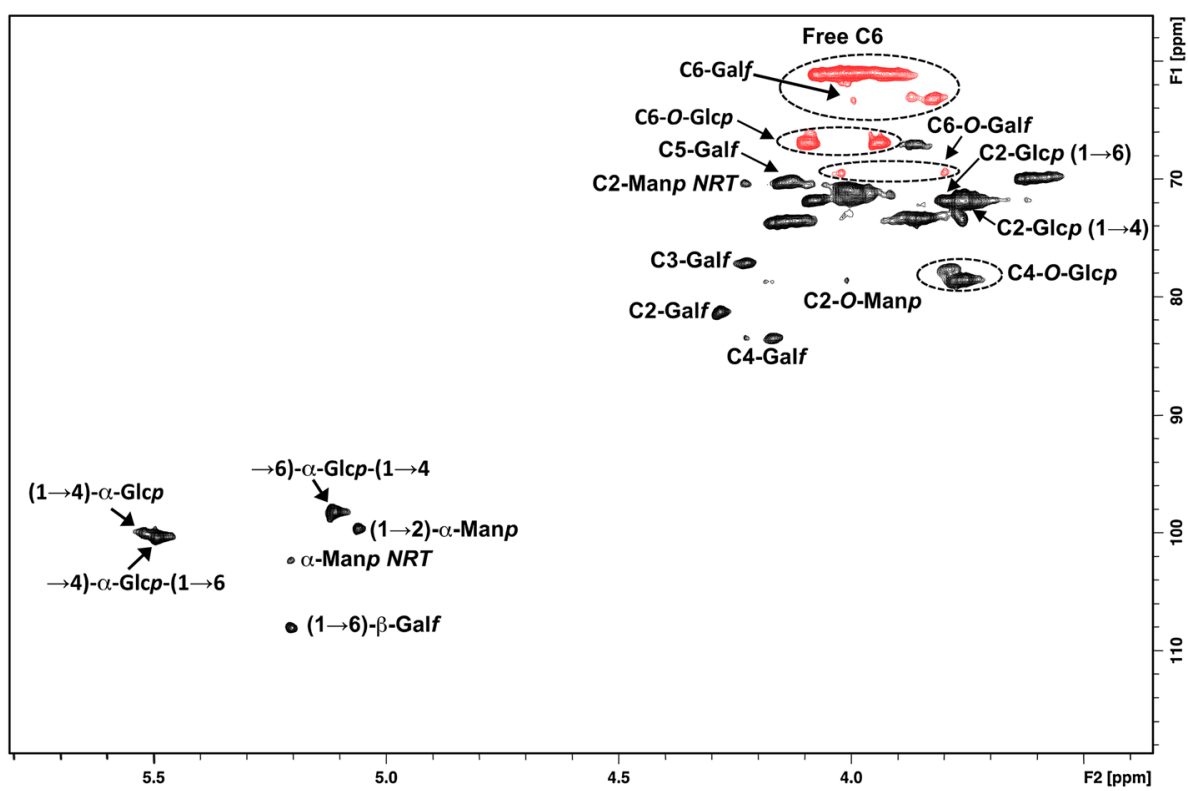




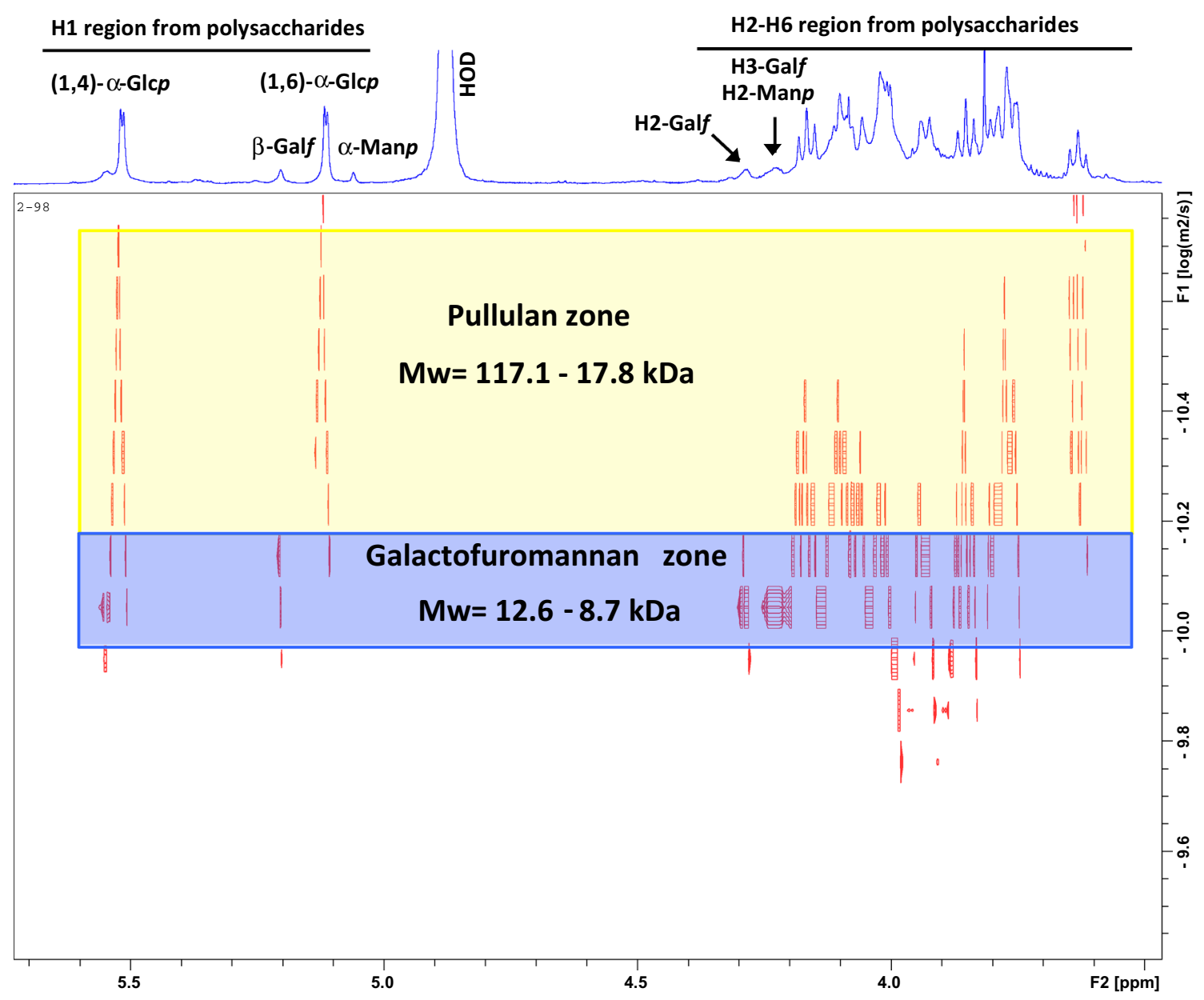

Fig. 4 2-D-DOSY spectra of $K$. petricola A95 extracellular polysaccharides. ${ }^{1} \mathrm{H}-\mathrm{NMR}$ spectra-the chemical shifts are shown on the $x$-axis. Values on the $y$-axis represent the log of the diffusion coef-

traits with other members of the phylogenetically heterogeneous group of black yeasts (Gueidan et al. 2011; Ruibal et al. 2008).

\section{Viscosity determination by atomic force microscopy}

To estimate diffusion- and convection-controlled processes in EPS, it is first necessary to quantify the viscosity of EPS. Here, we used an AFM-based approach for two reasons. First, only small amounts of dissolved extracellular polysaccharides were available and AFM measurements require less than $200 \mu$ of fluid. Second, micro-cantilever-based sensors act as nanomechanical, thermally excited harmonic resonators and the monitored vibration resembles Brownian motion (Franosch et al. 2011), thus an undisturbed thermodynamic equilibrium can be assumed during measurements. Viscosity was quantified by recording power density spectra (PDS) of a thermally excited cantilever in liquid EPS. At a resonance frequency $f_{\text {res }}$ of the cantilever, the spectra showed a maximum which can be ficient obtained at $303 \mathrm{~K}$. The main components are labelled in the spectra and the arrows cross the peaks in a specific $\log D$

described by means of a single harmonic oscillator (SHO) (Van Eysden and Sader 2007) or by a Lorentzian peak (Franosch et al. 2011). From a normalised Lorentzian fit, the quality factor $Q$ of the cantilever could be calculated by $Q=f_{\text {res }} / 2 \Gamma$ with resonance frequency $f_{\text {res }}$ and $2 \Gamma$ as the full width at half maximum (FWHM) of the peak. The quality factor $Q$ was inverse to the cantilever's damping $D$ and proportional to the kinematic viscosity $v=\frac{\eta}{\rho}$ (Tellechea et al. 2009), with $\eta$ as the dynamic viscosity and the fluid density $\rho$. To calibrate the sensing system glycerine-in-water mixtures were chosen since viscosity and density for any given fraction of glycerine are known (Cheng 2008). With a kinetic viscosity $v$ of $0.97 \times 10^{-6} \mathrm{~m}^{2} \mathrm{~s}^{-1}$, extracted $K$. petricola A95 extracellular polysaccharides ranged between 2 and 5\% glycerine (Fig. 5). 


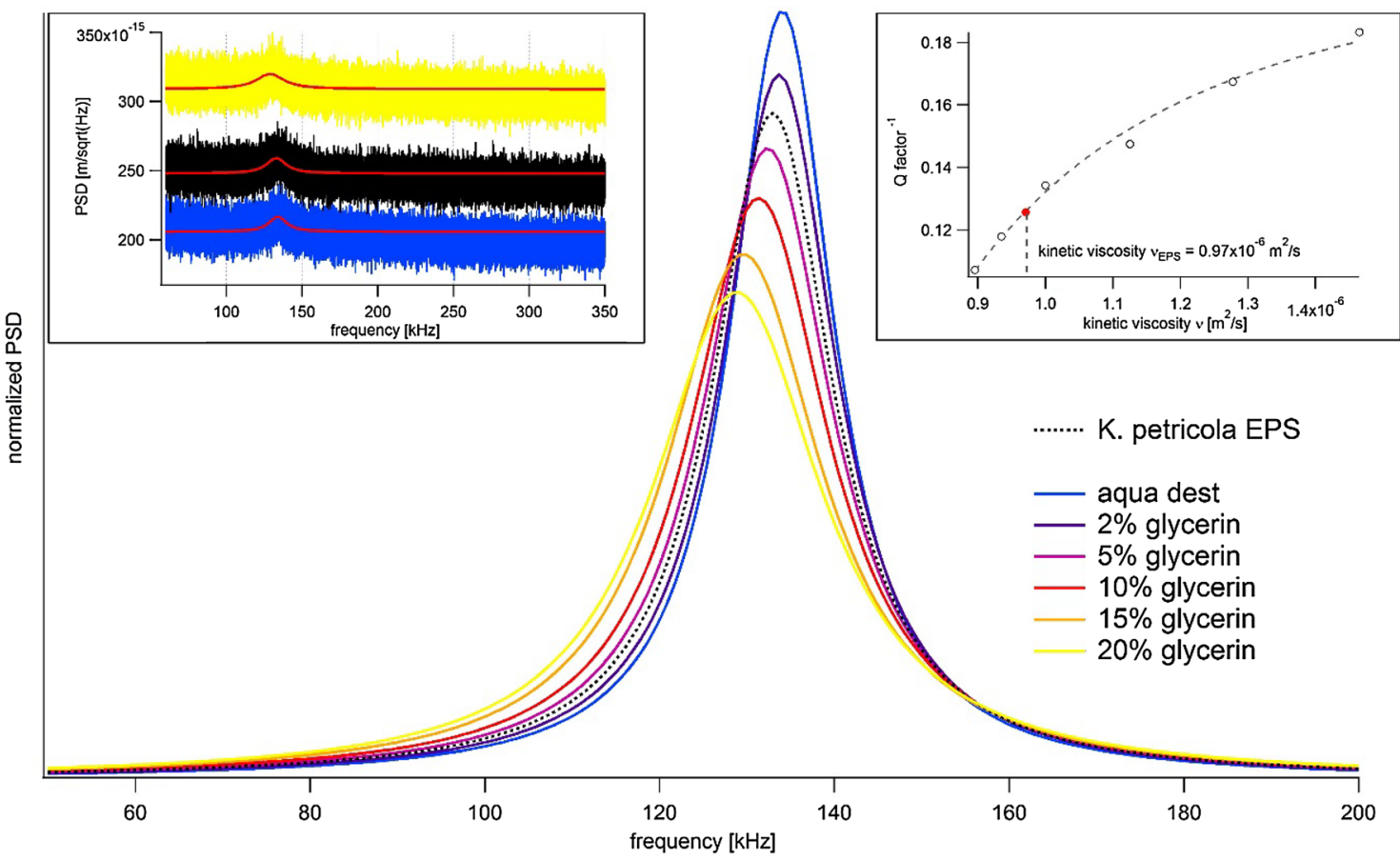

Fig. 5 Lorentzian curves fitted to power spectra density plots (PSD) and normalised to peak area (i.e., corresponding energy). The left inset presents three examples for the fitting of the noise thermal spectra. Inverse $Q$-factor (i.e., damping) for six different glycerine/

\section{EPS-induced corrosion}

In AFM, the output signal of the photodiode is correlated to the intensity of the reflected laser beam - thus the output signal of the photodiode decreases if the reflectance of the cantilever declines. Aluminium coatings are commonly used to enhance the reflectance of the cantilever surface above that of silicon. The output signal in this setup was measured to be $U_{\text {out }}>7 \mathrm{~V}$ in air and $<3 \mathrm{~V}$ in aqueous media. The silicon cantilever covered with a thin film of aluminium significantly changed its properties after exposure to extracellular A95 polysaccharides. The cantilever was rinsed with water after $1 \mathrm{~h}$ contact with suspension, dried $(<1 \mathrm{~h})$ and thereafter the reflectance of the surface dropped significantly $\left(U_{\text {out }}<4 \mathrm{~V}\right)$. Since absorbed material on the cantilever was not observed by Raman spectroscopy, displacement of the aluminium layer and changed reflection of the laser beam was expected. AFM topography scans of the previously immersed cantilever (compared to an unused cantilever) (Fig. 6a, b) verified the displacement revealed as well as drastic fluctuations in the aluminium layer thickness which could only be attributed to corrosion in the polysaccharide suspension (Fig. 6c).

Rather than a broadening of the peak at $t=0 \mathrm{~nm}$, which would be typical for increased roughness, a second silicon surface at approx. $T=-7 \mathrm{~nm}$ was visible. At those water mixtures and EPS with a fit describing $Q^{-1}(\nu)$ is shown in the right inset. The kinetic viscosity of extracellular polysaccharides (red marker) was determined to be $0.97 \times 10^{-6} \mathrm{~m}^{2} \mathrm{~s}^{-1}$

cantilever points, aluminium was completely corroded and at some points the sample height was even below the apparent silicon surface $(<t=-10 \mathrm{~nm})$. This would suggest that the silicon oxide layer was also corroded. EDX analyses showed that the Al layer was removed from the surface, leaving behind a silicon surface devoid of aluminium or its oxides (Fig. 7).

\section{Conclusions}

We developed widely applicable methods for the extraction of EPS, their analysis and characterisation of extracellular polysaccharides from melanised rock-inhabiting stressresistant fungi. Pullulan, an $\alpha-(1,4)-; \alpha-(1,6)$-glucan, was the main polysaccharide present $(\sim 80 \%)$ along with a branched galactofuromannan with a $\alpha-(1,2)$-linked Man $p$ main chain and a $\beta-(1,6)$-linked Gal $f$ side chain $(\sim 20 \%)$. The kinetic viscosity of $K$. petricola A95 extracellular polysaccharides ranged between the equivalent of 2-5\% (v/v) glycerine. EPS could thus have a profound effect on diffusion-dominated processes at material/SAB interfaces. Even within short exposures $(\approx 1 \mathrm{~h})$ the aluminium coatings of AFM cantilevers were significantly degraded by contact with extracellular polysaccharides of a rock-inhabiting fungal strain 


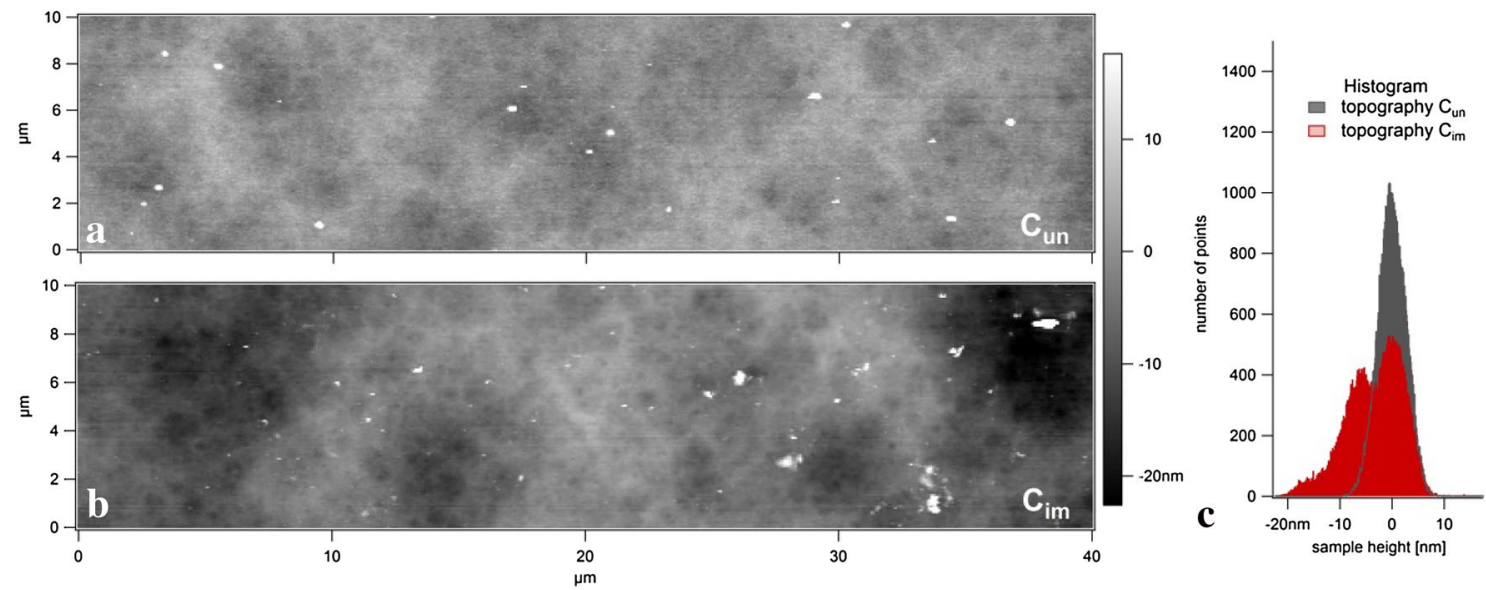

Fig. 6 Topography of an unused $\left(\mathbf{a}, C_{\text {un }}\right)$ and a used cantilever $\left(\mathbf{b}, C_{\mathrm{im}}\right)$ immersed for $1 \mathrm{~h}$ in $K$. petricola A95 extracellular polysaccharide solution. The histogram (c) demonstrates the increased surface roughness due to spatially selective corrosion (2nd left peak)

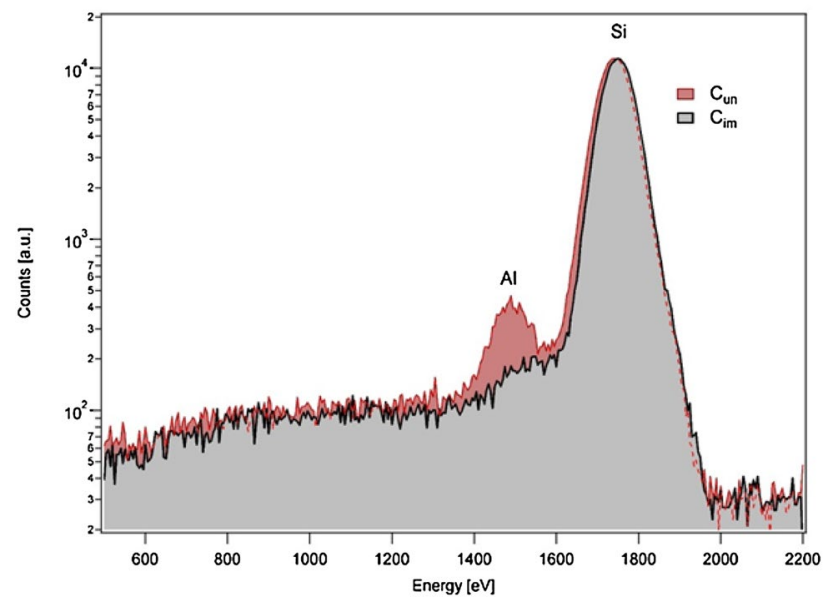

Fig. 7 EDX spectra of $C_{\text {un }}$ and $C_{\text {im }}$ without background subtraction. The spectrum of $C_{\mathrm{im}}$ shows neither a signal for aluminium (AlK $1485 \mathrm{eV}$ ) nor for organic compounds (carbon, C-K $250 \mathrm{eV}$; oxygen, $\mathrm{O}-\mathrm{K} 510 \mathrm{eV}$ ). Both curves were measured with identical sensitivities and integration times

clearly demonstrating their corrosive powers. Interestingly, the corrosive properties were not dependent on uronic acids which were not found in the extracellular polysaccharides of $K$. petricola A95.

Acknowledgements We thank Helena Mathies and Ute Schoknecht for their generous support and the possibility to use their GC-MS equipment and UFPR NMR Center for NMR analyses. Frank Milczewski gave us unstinting technical support, and Nicole Knabe provided the fungal strain. This work was supported financially by internal funds of the BAM, Conselho Nacional de Desenvolvimento Científico e Tecnológico (CNPq), FINEP (PRONEX-CARBOIDRATOS, PADCT II/ SBIO/CT-INFRA) and Fundação Araucária.

Open Access This article is distributed under the terms of the Creative Commons Attribution 4.0 International License (http://creativecomm ons.org/licenses/by/4.0/), which permits unrestricted use, distribution, and reproduction in any medium, provided you give appropriate credit to the original author(s) and the source, provide a link to the Creative Commons license, and indicate if changes were made.

\section{References}

Albersheim P, Nevins DJ, English PD, Karr A (1967) A method for the analysis of sugars in plant cell-wall polysaccharides by gasliquid chromatography. Carbohydr Res 5:340-345. https://doi. org/10.1016/S0008-6215(00)80510-8

Barreto-Bergter E, Figueiredo RT (2014) Fungal glycans and the innate immune recognition. Front Cell Infect Microbiol 4:1-17. https://doi.org/10.3389/Fcimb.2014.00145

Bender H, Lehmann J, Wallenfels K (1959) Pullulan, a extracellular glucan from Pullularia pullulans. Biochim Biophys Acta 36:309-316. https://doi.org/10.1016/0006-3002(59)90172-6

Blankenship JR, Mitchell AP (2006) How to build a biofilm: a fungal perspective. Curr Opin Microbiol 9:588-594. https://doi. org/10.1016/j.mib.2006.10.003

Bouveng HO, Mckay J, Lindberg B, Kiessling H (1962) Polysaccharides elaborated by Pullularia pullulans. 1. Neutral Glucan Synthesised from Sucrose Solutions. Acta Chem Scand 16:615-620. https://doi.org/10.3891/acta.chem.scand.16-0615

Breitenbach R, Toepel J, Dementyeva P, Knabe N, Gorbushina AA (2017) Snapshots of fungal extracellular matrices. In: Flemming HC, Neu TR, Wingender J (eds) The perfect slime-microbial extracellular polymeric substances (EPS). IWA Publishing, London. https://doi.org/10.2166/9781780407418

Cheng NS (2008) Formula for the viscosity of a glycerol-water mixture. Ind Eng Chem Res 47:3285-3288. https://doi.org/10.1021 /ie071349z

Cheng KC, Demirci A, Catchmark JM (2011) Pullulan: biosynthesis, production, and applications. Appl Microbiol Biot 92:29-44. https://doi.org/10.1007/s00253-011-3477-y

Chowdhary A, Perfect J, de Hoog GS (2015) Black molds and melanized yeasts pathogenic to humans. CSH Perspect Med 5:1-21. https://doi.org/10.1101/cshperspect.a019570

Ciucanu I, Caprita R (2007) Per- $O$-methylation of neutral carbohydrates directly from aqueous samples for gas chromatography 
and mass spectrometry analysis. Anal Chim Acta 585:81-85. https://doi.org/10.1016/j.aca.2006.12.015

Comte S, Guibaud G, Baudu M (2006) Relations between extraction protocols for activated sludge extracellular polymeric substances (EPS) and complexation properties of $\mathrm{Pb}$ and $\mathrm{Cd}$ with EPS part II. Consequences of EPS extraction methods on $\mathrm{Pb}^{2+}$ and $\mathrm{Cd}^{2+}$ complexation. Enzyme Microb Technol 38:246-252. https://doi.org/10.1016/j.enzmictec.2005.06.023

Dubois M, Gilles KA, Hamilton JK, Rebers PA, Smith F (1956) Colorimetric method for determination of sugars and related substances. Anal Chem 28:350-356. https://doi.org/10.1021/ Ac60111a017

Fang F, Lu WT, Shan Q, Cao JS (2014) Characteristics of extracellular polymeric substances of phototrophic biofilms at different aquatic habitats. Carbohydr Polym 106:1-6. https://doi. org/10.1016/j.carbpol.2014.02.010

Flemming HC, Wingender J, Szewzyk U, Steinberg P, Rice SA, Kjelleberg S (2016) Biofilms: an emergent form of bacterial life. Nat Rev Microbiol 14:563-575. https://doi.org/10.1038/nrmicro.2016 .94

Franosch T, Grimm M, Belushkin M, Mor FM, Foffi G, Forro L, Jeney S (2011) Resonances arising from hydrodynamic memory in Brownian motion. Nature 478:85-88. https://doi.org/10.1038 /nature 10498

Fujii N, Shinohara S, Ueno H, Imada K (1984) Polysaccharides produced by Aureobasidium sp. (black yeast). Kenkyu Hokoku Miyazaki Daigaku Nogakubu 31:253-262

Gadd GM (2007) Geomycology: biogeochemical transformations of rocks, minerals, metals and radionuclides by fungi, bioweathering and bioremediation. Mycol Res 111:3-49. https://doi.org/10.1016 /j.mycres.2006.12.001

Gorbushina A (2003) Microcolonial fungi: survival potential of terrestrial vegetative structures. Astrobiology 3:543-554. https://doi. org/10.1089/153110703322610636

Gorbushina AA (2007) Life on the rocks. Environ Microbiol 9:16131631. https://doi.org/10.1111/j.1462-2920.2007.01301.x

Gorbushina AA, Broughton WJ (2009) Microbiology of the atmosphere-rock interface: how biological interactions and physical stresses modulate a sophisticated microbial ecosystem. Annu Rev Microbiol 63:431-450. https://doi.org/10.1146/annurev.micr o.091208.073349

Gorbushina AA, Krumbein WE, Hamman CH, Panina L, Soukharjevski S, Wollenzien U (1993) Role of black fungi in colour change and biodeterioration of antique marbles. Geomicrobiol J 11:205-221

Gorbushina AA, Kotlova ER, Sherstneva OA (2008) Cellular responses of microcolonial rock fungi to long-term desiccation and subsequent rehydration. Stud Mycol 61:91-97. https://doi.org/10.3114 /sim.2008.61.09

Gueidan C, Ruibal C, de Hoog GS, Gorbushina AA, Untereiner WA, Lutzoni F (2008) An extremotolerant rock-inhabiting ancestor for mutualistic and pathogen-rich fungal lineages. Stud Mycol 61:111-119

Gueidan C, Ruibal C, De Hoog GS, Schneider H (2011) Rock-inhabiting fungi originated during periods of dry climate in the late Devonian and middle Triassic. Fungal Biol 115:987-996. https:// doi.org/10.1016/j.funbio.2011.04.002

Kobayashi H et al (1995) Assignment of H-1 and C-13 NMR chemicalshifts of a D-mannan composed of alpha-(1-]2)-linkage and alpha(1-]6)-linkage obtained from Candida-kefyr IFO-0586. Strain Carbohydr Res 267:299-306. https://doi.org/10.1016/0008-6215 (94)00299-u

Kuncheva M, Panchev I, Pavlova K, Russinova-Videva S, Georgieva K, Dimitrova S (2013) Functional characteristics of an exopolysaccharide from antarctic yeast strain Cryptococcus laurentii $\mathrm{Al}(62)$.
Biotechnol Equip 27:4098-4102. https://doi.org/10.5504/bbeq .2013.0009

Liang Z, Li W, Yang S, Du P (2010) Extraction and structural characteristics of extracellular polymeric substances (EPS), pellets in autotrophic nitrifying biofilm and activated sludge. Chemosphere 81:626-632. https://doi.org/10.1016/j.chemosphere.2010.03.043

Liu H, Fang HH (2002) Extraction of extracellular polymeric substances (EPS) of sludges. J Biotechnol 95:249-256

Mota R et al (2013) Production and characterization of extracellular carbohydrate polymer from Cyanothece sp. CCY 0110. Carbohydr Polym 92:1408-1415. https://doi.org/10.1016/j.carbpol.2012 .10 .070

Nai C et al (2013) Nutritional physiology of a rock-inhabiting, model microcolonial fungus from an ancestral lineage of the Chaetothyriales (Ascomycetes). Fungal Genet Biol 56:54-66. https://doi. org/10.1016/j.fgb.2013.04.001

Noack-Schonmann S et al (2014) Genetic transformation of Knufia petricola A95-a model organism for biofilm-material interactions. AMB Express. https://doi.org/10.1186/s13568-014-0080-5

Onofri S et al (2012) Survival of rock-colonizing organisms after 1.5 years in outer space. Astrobiology 12:508-516. https://doi. org/10.1089/ast.2011.0736

Pavlova K, Rusinova-Videva S, Kuncheva M, Kratchanova M, Gocheva M, Dimitrova S (2011) Synthesis and characterization of an exopolysaccharide by antarctic yeast strain Cryptococcus laurentii AL(1)(0)(0). Appl Biochem Biotechnol 163:1038-1052. http s://doi.org/10.1007/s12010-010-9107-9

Pellicer-Nacher C, Domingo-Felez C, Mutlu AG, Smets BF (2013) Critical assessment of extracellular polymeric substances extraction methods from mixed culture biomass. Water Res 47:55645574. https://doi.org/10.1016/j.watres.2013.06.026

Prajapati VD, Jani GK, Khanda SM (2013) Pullulan: an exopolysaccharide and its various applications. Carbohydr Polym 95:540-549. https://doi.org/10.1016/j.carbpol.2013.02.082

Ragon M, Restoux G, Moreira D, Moller AP, Lopez-Garcia P (2011) Sunlight-exposed biofilm microbial communities are naturally resistant to Chernobyl ionizing-radiation levels. PLoS One 6:e21764. https://doi.org/10.1371/journal.pone.0021764

Ruibal C, Platas G, Bills GF (2008) High diversity and morphological convergence among melanised fungi from rock formations in the Central Mountain System of Spain. Persoonia 21:93-110. https:// doi.org/10.3767/003158508x371379

Sassaki GL, Souza LM (2013) Mass spectrometry strategies for structural analysis of carbohydrates and glycoconjugates. In: Coelho DAV (ed) Tandem mass spectrometry-molecular characterization. InTech, Rijeka, London, pp 81-115

Sassaki GL, Gorin PAJ, Souza LM, Czelusniak PA, Iacomini M (2005) Rapid synthesis of partially $O$-methylated alditol acetate standards for GC-MS: some relative activities of hydroxyl groups of methyl glycopyranosides on Purdie methylation. Carbohydr Res 340:731-739. https://doi.org/10.1016/j.carres.2005.01.020

Sassaki GL, Czelusniak PA, Vicente VA, Zanata SM, Souza LM, Gorin PAJ, Iacomini M (2011) Some biomolecules and a partially $O$-acetylated exo-galactomannan containing beta-Galf units from pathogenic Exophiala jeanselmei, having a pronounced immunogenic response. Int J Biol Macromol 48:177-182. https://doi. org/10.1016/j.ijbiomac.2010.10.017

Scalzi G, Selbmann L, Zucconi L, Rabbow E, Horneck G, Albertano P, Onofri S (2012) LIFE experiment: isolation of cryptoendolithic organisms from Antarctic colonized sandstone exposed to space and simulated Mars conditions on the international space station. Orig Life Evol Biosphere J Int Soc Study Orig Life 42:253-262. https://doi.org/10.1007/s11084-012-9282-5 
Selbmann L, de Hoog GS, Mazzaglia A, Friedmann EI, Onofri S (2005) Fungi at the edge of life: cryptoendolithic black fungi from Antarctic desert. Stud Mycol 51:1-32

Selbmann L, Zucconi L, Isola D, Onofri S (2014) Rock black fungi: excellence in the extremes, from the Antarctic to space. Curr Genet 61(335):345. https://doi.org/10.1007/s00294-014-0457-7

Sowa W, Blackwood AC, Adams GA (1963) Neutral extracellular glucan of Pullularia pullulans (de Bary) Berkhout. Can J Chem 41:2314-2319

Tellechea E, Johannsmann D, Steinmetz NF, Richter RP, Reviakine I (2009) Model-independent analysis of QCM data on colloidal particle adsorption. Langmuir 25:5177-5184. https://doi.org/10.1021 /la803912p

Tourney J, Ngwenya BT (2014) The role of bacterial extracellular polymeric substances in geomicrobiology. Chem Geol 386:115-132. https://doi.org/10.1016/j.chemgeo.2014.08.011

Van Eysden CA, Sader JE (2007) Frequency response of cantilever beams immersed in viscous fluids with applications to the atomic force microscope: arbitrary mode order. J Appl Phys. https://doi. org/10.1063/1.2654274
Vinogradov E, Petersen B, Bock K (1998) Structural analysis of the intact polysaccharide mannan from Saccharomyces cerevisiae yeast using H-1 and C-13 NMR spectroscopy at $750 \mathrm{MHz}$. Carbohydr Res 307:177-183

Wang ZF, He Y, Huang LJ (2007) An alternative method for the rapid synthesis of partially $O$-methylated alditol acetate standards for GC-MS analysis of carbohydrates. Carbohydr Res 342:21492151. https://doi.org/10.1016/j.carres.2007.05.028

Wollenzien U, de Hoog GS, Krumbein W, Uijthof JM (1997) Sarcinomyces petricola, a new microcolonial fungus from marble in the Mediterranean basin. Antonie Van Leeuwenhoek 71:281-288

Zakharova K, Tesei D, Marzban G, Dijksterhuis J, Wyatt T, Sterflinger K (2013) Microcolonial fungi on rocks: a life in constant drought? Mycopathologia 175:537-547. https://doi.org/10.1007 /s11046-012-9592-1

Zhang Y, Kong H, Fang Y, Nishinari K, Phillips GO (2013) Schizophyllan: a review on its structure, properties, bioactivities and recent developments. Bioactive Carbohydr Diet Fibre 1:53-71. https://doi.org/10.1016/j.bcdf.2013.01.002 